\title{
Case Files of the New York City Poison Control Center: Paradichlorobenzene-Induced Leukoencephalopathy
}

\author{
Stephanie H. Hernandez • Sage W. Wiener • \\ Silas W. Smith
}

Published online: 7 April 2010

(C) American College of Medical Toxicology 2010

Keywords Ataxia $\cdot$ Encephalopathy

Leukoencephalopathy $\cdot$ Moth ball(s) Paradichlorobenzene . White matter disease

\section{Case Presentation}

A 44-year-old man was brought to the emergency department by emergency medical services after he was discovered lying supine on his apartment floor. He was accompanied by his sister, who had decided to visit him after his absence from a family function. Worsening "bizarre" behavior had been noted by family members for 4 weeks, characterized by anorexia, social withdrawal, flat affect, and alogia. Prior to

The authors have neither financial interest in any commercial products mentioned nor the companies that produce them.

No outside funding was received.

This case was presented at the ACMT Medical Toxicology 11th Annual CPC Competition at the 2009 North American Congress of Clinical Toxicology Annual Meeting, San Antonio, TX, USA, September 22, 2009.

S. H. Hernandez $(\bowtie) \cdot S$. W. Smith

New York City Poison Control Center,

455 First Avenue, Room 123,

New York, NY 10016, USA

e-mail: hernas07@nyumc.org

S. H. Hernandez $\cdot$ S. W. Smith

New York University School of Medicine,

New York, NY, USA

S. W. Wiener

State University of New York Downstate Medical Center,

New York, NY, USA his illness, he was described as functional, independent, gainfully employed, and social.

The patient had mild mental retardation and hypertension. There was no history of diagnosed psychiatric illness, although his family suspected pica. Medications included an unknown antihypertensive with which he was not compliant. He occasionally used marijuana and alcohol, without history of other abused drugs. The patient's sister reported significant weight loss over several months. There had been no apparent fevers, cough, vomiting, diarrhea, or convulsions. On physical examination, he appeared drowsy, was markedly cachectic, and emanated an atypical aromatic body odor. Initial vital signs were: blood pressure $154 / 90 \mathrm{mmHg}$, heart rate $98 / \mathrm{min}$, respiratory rate $20 / \mathrm{min}$, rectal temperature $37.4^{\circ} \mathrm{C}$, and room air oxygen saturation $97 \%$. Head, neck, chest, and abdominal examinations were unremarkable. He had dry, scaling, and ichthyotic skin. He was oriented to person and place, but not to time, date, or indication for hospitalization. Limited cranial nerve evaluation was normal. Pain and light-touch sensation were unaffected. Hyperreflexia (without clonus) and cogwheel rigidity were noted in both lower extremities; upper extremities were normal. Plantar reflexes were normal bilaterally. Muscle bulk, tone, and strength were normal. The patient was unable to stand without support and unable to ambulate, apparently due to impaired equilibrioception. He could follow simple one-step commands. He would speak a few words when asked simple questions, and he avoided eye contact.

Serum electrolytes (sodium, potassium, chloride, calcium, and magnesium) and serum glucose were normal. Tests of hepatic and renal function were: AST $53 \mathrm{U} / 1(0-40 \mathrm{U} / \mathrm{l})$, ALT $25 \mathrm{U} / 1$ (10-40 U/l), alkaline phosphatase $88 \mathrm{U} / 1$ (35-145 U/l), total bilirubin $6.84 \mu \mathrm{mol} / \mathrm{l}(0.4 \mathrm{mg} / \mathrm{dl})(0-20.52 \mu \mathrm{mol} / \mathrm{l} ; 0$ $1.2 \mathrm{mg} / \mathrm{dl})$, ammonia $31 \mu \mathrm{mol} / \mathrm{l}(43.42 \mu \mathrm{g} / \mathrm{dl})(11-35 \mu \mathrm{mol} / \mathrm{l}$; 
15.41-49.02 $\mu \mathrm{g} / \mathrm{dl})$, BUN $11.42 \mathrm{mmol} / \mathrm{l}(31.99 \mathrm{mg} / \mathrm{dl})$ (2.86-7.85 $\mathrm{mmol} / \mathrm{l} ; 8.01-21.99 \mathrm{mg} / \mathrm{dl})$, and creatinine $136.14 \mu \mathrm{mol} / \mathrm{l}(1.54 \mathrm{mg} / \mathrm{dl})(35.36-106.08 \mu \mathrm{mol} / \mathrm{l} ; 0.4$ $1.2 \mathrm{mg} / \mathrm{dl})$. Microcytic anemia was present without evidence of hemolysis; hemoglobin $99.0 \mathrm{~g} / 1$ (9.9 g/dl) (140-180 g/l; $14.0-18.0 \mathrm{~g} / \mathrm{dl})$, hematocrit $34.3 \%(42.0-52.0 \%)$, MCV $65.3 \mathrm{fl}$ (71.4-94.6 fl), RDW 25.9\% (11.5-15.1\%). Leukocyte count, differential, T cell subpopulations, and platelets were unremarkable. Nonspecific acute-phase reactants were abnormal: erythrocyte sedimentation rate, $47 \mathrm{~mm} / \mathrm{h}(0-15 \mathrm{~mm} / \mathrm{h})$, and serum C-reactive protein, $3,981 \mathrm{nmol} / 1(41.8 \mathrm{mg} / \mathrm{l})(95.2-$ $381 \mathrm{nmol} / \mathrm{l} ; 1.0-4.0 \mathrm{mg} / \mathrm{l})$. Tests for syphilis, Lyme disease, and HIV infection were negative, and thyroid studies were within normal limits. Additional serum studies included folate $12.28 \mathrm{nmol} / 1(5.42 \mathrm{ng} / \mathrm{ml})(2.49-45.32 \mathrm{nmol} / \mathrm{l} ; 1.1-20 \mathrm{ng} / \mathrm{ml})$, vitamin $\mathrm{B}_{12} 735 \mathrm{pmol} / 1$ (996 pg/ml) (155-812 pmol/l; 210 $1,100 \mathrm{pg} / \mathrm{ml})$, and ceruloplasmin $441.00 \mathrm{mg} / 1(44.1 \mathrm{mg} / \mathrm{dl})$ (220-610 mg/l; 22.0-61.0 mg/dl). Cerebrospinal fluid (CSF) was acellular with normal protein and glucose. CSF bacterial and viral cultures and cryptococcal antigen were negative, along with CSF evaluation for prion disease. An atypical viral encephalitis panel was negative. Serum ethanol, methanol, and ethylene glycol were $0 \mathrm{mmol} / \mathrm{l}(0 \mathrm{mg} / \mathrm{dl})$, and urine toxicology was negative for barbiturates, cocaine, methadone, and opioid metabolites. Urine benzodiazepines were detected barely above the reporting threshold at $1.29 \mu \mathrm{mol} / 1(371 \mathrm{ng} / \mathrm{ml})$, consistent with ED administration of midazolam to facilitate computed tomography (CT) imaging.

No clinical seizure activity was evident, and two separate electroencephalograms demonstrated only focal slowing in the temporal lobes without epileptogenic discharges. A CT performed the day of admission and a magnetic resonance imaging (MRI) of the brain without contrast performed within a week were without abnormality. However, a later reevaluation of the initial MRI imaging suggested a signal intensity on $\mathrm{T} 2$ and fluid-attenuated inversion recovery (FLAIR) images in the subcortical white matter of the anterior temporal lobes.

\section{What Etiologies Should Be Considered in Leukoencephalopathy?}

A leukoencephalopathy implies a central nervous system (CNS) disorder or disease process in which the white matter is the primary target (Table 1). Classification may be based on anatomical, clinical, etiological, histopathological, and/or radiological variables. Reversible posterior leukoencephalopathy syndrome (RPLS) is characterized by alteration in mental status, hypertension, visual disturbance, predominant parietal and occipital lobe involvement, and recovery within 2 weeks [1]. Osmotic demyelination syndrome — characterized by myelin destruction in pontine and other structures, acute change in mental status, progressive spastic quadriparesis, and pseudobulbar palsy -is most commonly associated with ethanol abuse and rapid correction of hyponatremia. The term central pontine myelinolysis has been applied when damage is restricted to the pons. Progressive multifocal leukoencephalopathy is associated with a specific etiology (a polyomavirus). The particularly severe multifocal or disseminated necrotizing leukoencephalopathy, most often seen as a complication of chemotherapy, demonstrates widespread histopathological lesions of necrosis, myelin loss, edema, and axonal swelling [2]. Acute disseminated (perivenous) encephalomyelitis typically occurs following childhood febrile illness or vaccination, with perivascular demyelination and inflammatory changes. Acute hemorrhagic leukoencephalitis is a generally fulminant demyelinating disorder with associated hemorrhage and perivascular demyelination. Sophisticated radiological classification methods exist to further characterize the leukoencephalopathies [3, 4].

Although some may manifest in adulthood, heritable disorders affecting white matter are usually evident early in life $[5,6]$. Insufficient metabolic substrates to support white matter integrity, including hypoxia, may result in leukoencephalopathy [7-9]. Sudden elevation in mean arterial pressure - seen in eclampsia or severe hypertension - may exceed CNS vascular autoregulatory capability, resulting in vasogenic edema and leukoencephalopathy [10]. This also may occur secondary to other vascular disorders $[11,12]$. Trauma, hydrocephalus, and infection may produce leukoencephalopathy [13-15]. Inflammatory demyelinating disorders include prototypic multiple sclerosis and its less common variants $[16,17]$. Toxin-induced leukoencephalopathy is rare and considered once clinical evaluation has ruled out infectious, metabolic, genetic, demyelinating, and structural and traumatic etiologies. Specific toxins are investigated upon obtaining a history of pertinent exposure.

\section{Case Continuation}

Mild renal impairment resolved with hydration. Empiric trials of antibacterial and antiviral antibiotics, anticonvulsants, antipsychotics, mood stabilizers, and vitamins failed to produce any response. These included acyclovir, phenytoin, lorazepam, quetiapine, valproic acid, folate, iron, and thiamine. A benzodiazepine-facilitated interview did not suggest a conversion disorder. He clinically deteriorated over a month. He progressed from saying few words to grunting occasionally when physically examined, to complete catatonia, without response to voice or pain. He developed upperextremity cogwheel-like rigidity and hyperactive reflexes and lower-extremity clonus. Discontinuation of anticonvulsants, antipsychotics, and mood stabilizers due to concern for serotonin syndrome or drug-induced encephalopathy produced no benefit. He ultimately required a percutaneous 
Table 1 Nontoxicological differential diagnosis of leukoencephalopathy
This is not a complete list

$A L D$ adrenoleukodystrophy, MELAS mitochondrial encephalomyopathy, lactic acidosis, and stroke-like symptoms, $M E R F F$ myoclonus epilepsy with ragged red fibers, SSPE subacute sclerosing panencephalitis
Heritable disorders

Amino acid disorders

Dihydropteridine reductase deficiency

Gyrate atrophy of the choroids and retina

Hyperprolinemia

Maple syrup urine disease

Nonketotic hyperglycinemia

Ornithine transcarbamylase deficiency

Phenylketonuria

Autoimmune thyroid disease

Biotinidase deficiency

Carbohydrate disorders

Congenital disorders of glycosylation

Galactosemia

Genetic leukodystrophies

Adrenomyeloneuropathy

Adult cerebral X-linked ALD

Alexander disease

Canavan disease

Childhood cerebral X-linked ALD

Female heterozygote form of ALD

Globoid cell leukodystrophy (Krabbe disease)

Hypomyelinating disorders

Leukodystrophy with neuroaxonal spheroids

Metachromatic leukodystrophy

Vanishing white matter disease

Lipid metabolism disorders

Cerebrotendinous xanthomatosis

Lysosomal disorders

Fabry's disease

GM1 gangliosidosis

GM2 gangliosidosis

Mucopolysaccharidosis types 1 and 2

Niemann-Pick type C

Organic acid disorders

Glutaric aciduria type 1

Methylmalonic acidemia

Propionic acidemia

Sjögren Larsson syndrome

Mitochondrial cytopathies

Kearns Sayre syndrome

Leigh's disease

MELAS

MERFF

Metal metabolism disorders

Menke's kinky hair disease

Molybdenum cofactor deficiency

Peroxisomal disorders

$\beta$-Oxidation disorders
Nonheritable disorders

Autoimmune thyroid disease (acquired)

Demyelinating disorders

Acute disseminated encephalomyelitis

Acute hemorrhagic leukoencephalitis

Balo's concentric sclerosis

Multiple sclerosis

Marburg variant acute multiple sclerosis

Neuromyelitis optica

Osmotic demyelination syndrome

Tumefactive multiple sclerosis

Infectious

Cytomegalovirus (CMV)

Herpes simplex virus (HSV)

Human immunodeficiency virus (HIV)

Human T cell lymphotropic virus (HTLV)

JC polyomavirus

Lyme disease

Measles-associated SSPE

Rubella panencephalitis

Simian vacuolating virus 40

Varicella zoster virus (VZV)

Metabolic disorders

Folate deficiency

Thiamine deficiency

Vitamin $\mathrm{B}_{12}$ deficiency

Hypoxia

Vascular disorders

Binswanger disease

Cerebral amyloid angiopathy

Eclampsia

Hypertension

Miscellaneous

Hydrocephalus

Trauma 
Fig. 1 Approximately 1 month after presentation, representative images of a brain MRI with gadolinium: T2-weighted (a) and FLAIR (b) images. Both demonstrate confluent, symmetric, and bilateral high signal in the periventricular white matter, sparing the subcortical U-fibers
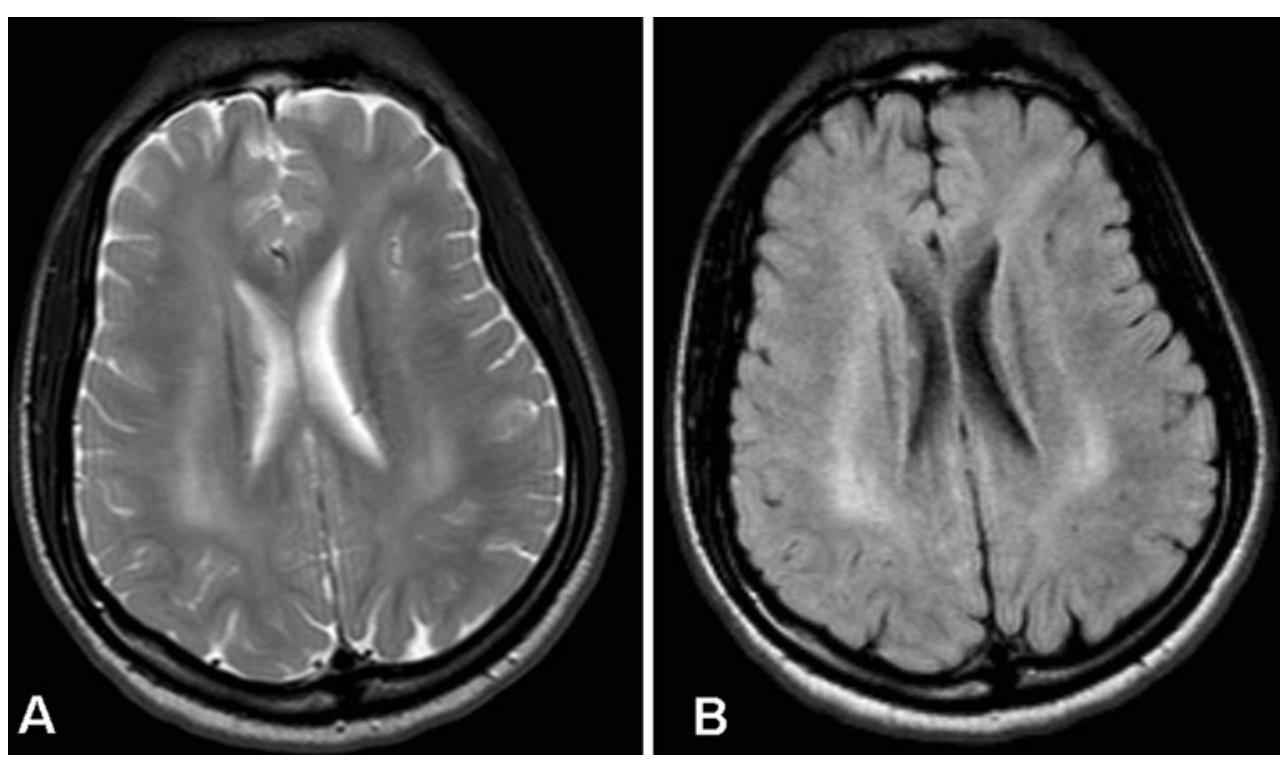

gastrostomy tube for feeding. Subsequently, a repeat MRI with gadolinium demonstrated confluent symmetric and bilateral signal intensity on T2 and FLAIR images in the periventricular white matter (Fig. 1). Similar finding were noted in the posterior cingulate gyri and splenium of the corpus callosum, and the signal intensity in the subcortical white matter of the anterior temporal lobes had increased since the initial MRI.

\section{What Is "Coasting"?}

Coasting is the phenomenon by which toxicity persists and clinical deterioration occurs despite discontinuation of exposure to a toxin. This has been described with many neurotoxins such as thalidomide, hydrocarbon sniffing with tetraethyl lead, $n$-hexane (and methyl- $n$-butyl ketone and 2,5-hexanedione), chemotherapeutic agents, antivirals, and pyridoxine [18-23].

\section{What Toxins Induce Leukoencephalopathy?}

Potential white matter toxins include abused or misused substances, antimicrobials, antineoplastics, immune modulators, environmental and industrial toxins, and other agents (Table 2). Antineoplastic therapies, including radiation, comprise the largest group. The vulnerability of oligodren-

Table 2 Xenobiotics associated with leukoencephalopathy

\begin{tabular}{|c|c|c|c|c|c|c|}
\hline $\begin{array}{l}\text { Abused or misused } \\
\text { substances }\end{array}$ & $\begin{array}{l}\text { Antimicrobial } \\
\text { agents }\end{array}$ & $\begin{array}{l}\text { Antineoplastic } \\
\text { agents }\end{array}$ & & $\begin{array}{l}\text { Cytokines and } \\
\text { immune modulators }\end{array}$ & $\begin{array}{l}\text { Environmental and } \\
\text { occupational toxins }\end{array}$ & Miscellaneous \\
\hline Cocaine/“crack" & Acyclovir & Bleomycin & Gemcitabine & Azathioprine & Arsenic & Cranial irradiation \\
\hline Ephedra & Amphotericin B & Bortezomib & L-Asparaginase & Bevacizumab & Carbon disulfide & Ethylene glycol \\
\hline Ethanol & Hexachlorophene & Capecitabine & Melphalan & Cyclosporine A & Carbon monoxide & Lithium \\
\hline Heroin (intravenous) & Levamisole & Carboplatin & Methotrexate & Dexamethasone & Carbon tetrachloride & Methanol \\
\hline Heroin (pyrosylate) & Linezolid & Carmofur & Nimustine & Erythropoietin & Tetraethyl lead & Thalidomide \\
\hline MDMA & & Carmustine & Paclitaxel & Etanercept & Triethyl tin & \\
\hline Methadone & & Cisplatin & Sorafenib & Everolimus & Trimethyl tin & \\
\hline Oxycodone (inhalation) & & Cyclophosphamide & Sunitinib & Interferon alpha & & \\
\hline Paradichlorobenzene & & Cytarabine & Tegafur & Interleukin 2 & & \\
\hline Psilocybin & & Doxorubicin & Thiopeta & Prednisone & & \\
\hline \multirow[t]{3}{*}{ Toluene } & & Etoposide & Vinblastine & Prednisolone & & \\
\hline & & 5-Fluorourcil & Vincristine & Rituximab & & \\
\hline & & Fludarabine & & Tacrolimus & & \\
\hline
\end{tabular}

This is not a complete list. Xenobiotics have been reported to be associated with leukoencephalopathy alone or in combination with other agents $M D M A$ 3,4-methylenedioxymethamphetamine, VEGF vascular endothelial growth factor 
drocytes and vasculature to radiation accounts for leukoencephalopathy seen in some patients. Additionally, in vitro studies of carmustine, cisplatin, and cytarabine suggest that chemotherapeutic agents are more toxic for the progenitor cells of the CNS and for nondividing oligodendrocytes than they are for multiple cancer cell lines [24]. Pathology can range from demyelination and gliosis to frank necrosis $[25$, 26]. In addition, risk for encephalopathy increases appreciably when chemotherapeutic agents are added to radiation regimens. White matter pathology ranges from radiologically detectable asymptomatic disease to a fatal necrotizing leukoencephalopathy [27-29]. RPLS is associated with an increasing number of anticancer drugs. Although the underlying mechanism is unknown, vasogenic edema, disruption of the blood brain barrier, hypertension, and electrolyte abnormalities have been suggested. RPLS may be associated with alteration in mental status, hypertension, seizure, visual disturbance ranging from blurred vision to cortical blindness, headache, and focal neurologic deficits. Hyperintense T2 signal in parietal and occipital lobe white matter, with cortical and subcortical edema on MRI, supports the diagnosis. It is thought to be reversible within 2 weeks if the offending agent is removed and hypertension is appropriately treated [1, 30-32]. Cisplatin, 5-fluorouracil, gemcitabine, cyclophosphamide, and methotrexate are among the most common chemotherapeutics associated with RPLS [33-37]. However, the list of single agents and combination chemotherapy regimens associated with RPLS and leukoencephalopathy in general is extensive and continues to grow [38-42]. Prednisone and prednisolone have been associated with leukoencephalopathy, usually as part of a chemotherapy combination regimen, particularly CHOP (cyclophosphamide, hydroxydaunorubicin, oncovin, and prednisone/prednisolone) [27, 36].

Other immunosuppressive and immune modulating drugs have been reported to precede the onset of leukoencephalopathy. Bevacizumab (antivascular endothelial growth factor A), dexamethasone, tacrolimus, etanercept (TNF antagonist), interleukin 2, and alpha interferon have been implicated in RPLS [43-48]. Immunosuppressive therapy employing cyclosporine A for stem cell transplant, renal transplant, and focal glomerulosclerosis has resulted in leukoencephalopathy including RPLS and fatal leukoencephalopathy [49]. Treatment of chronic anemia with erythropoietin, particularly in end-stage renal failure patients, can cause hypertension associated with posterior leukoencephalopathy [50]. Although some agents like interleukin 2, interferon, and prednisone have been reported to precipitate reversible posterior leukoencephalopathy, they have also been used to treat progressive multifocal leukoencephalopathy with variable success [51,52].

Several antimicrobials are associated with leukoencephalopathy. Levamisole, as an immunomodulating agent for recurrent aphthous ulcers, as an anthelmintic, and as an adjuvant for chemotherapy, particularly with 5-fluorouracil (5-FU), may induce multifocal inflammatory leukoencephalopathy. Motor weakness, dysphasia or aphasia, cognitive impairment, and gait abnormalities are among the major clinical features. The MRI may reveal diffuse hyperintensity of signal from periventricular white matter on MRI and/or individual demyelinating lesions [53, 54]. Amphotericin B can cause a diffuse noninflammatory leukoencephalopathy that can be fatal. Postmortem brain analysis demonstrated florid astrogliosis, demyelination, and infiltration of the hemispheric white matter by foamy macrophages [55, 56]. Rare cases of linezolid- and acyclovir-induced posterior leukoencephalopathy have also been reported $[57,58]$. The use of hexachlorophenecontaining soaps to bathe infants was discontinued after dermal absorption resulted in encephalopathy and death, particularly in premature infants. This vacuolar encephalopathy afflicted the white matter, characterized by wide intralamellar spaces or "splitting" of myelin sheaths [59].

Chronic alcoholism may be associated with significant white matter pathology. The ethanol metabolites acetaldehyde and related products of lipid peroxidation bind directly to tissues and elicit an immune-mediated response, with subsequent white matter damage. Alcoholics deficient in thiamine may develop cerebral lactic acidosis, swelling of astrocytes, oligodendrocytes, myelin fibers, and neuronal dendrites. Similarly, consumption of thiaminase-containing foodstuffs, such as Anaphe venata (African silkworm) larvae, carp, and bracken fern may produce white matter lesions particularly in the paraventricular regions $[60,61]$. Children and adolescents with prenatal exposures to ethanol have demonstrated similar white matter changes as seen in adults. Alcoholics with chronic malnutrition and serum electrolyte abnormalities are at risk for osmotic demyelination syndrome, often in association with Wernicke's encephalopathy and polyneuropathy. Extensive noninflammatory demyelination occurs within the pons, basal ganglia, thalami, and deep cerebral white matter and less commonly in the lateral geniculate bodies and hippocampi. Marchiafava-Bignami disease, a rare complication of chronic alcoholism, is characterized by demyelination and necrosis of the corpus callosum [62]. Patients who survive methanol or ethylene glycol intoxication may have white matter changes ranging from nonenhancing areas of necrosis within peripheral white matter to general cerebellar white matter abnormalities. Similar abnormalities may result from anoxic-ischemic insults or severe metabolic disturbances [63-65].

Although opiates may produce hypoventilation and subsequent hypoxic brain injury resulting in white matter abnormalities, leukoencephalopathy is also reported without preceding respiratory compromise. Methadone abuse 
has been reported to precede catatonia and extrapyramidal symptoms, with MRI images demonstrating extensive, symmetric signal-intensity abnormalities in deep white matter. These findings have been compared to the more familiar toxic leukoencephalopathy from heroin pyrosylate $[66,67]$. In the 1980s, "chasing the dragon," inhaling the thick white pyrosylate generated by heating heroin base on aluminum foil, was implicated in an unexplained spongiform encephalopathy in the Netherlands. Similar cases were reported in other parts of Europe and the USA [68, 69]. Clinical features included abulia, ataxia, speech abnormalities, spastic paraparesis, and hypotonia with prominent cerebellar and cerebral white matter destruction on MRI [70, 71]. Although initially thought to be related to the inhalation of aluminum fumes, it is likely attributed to some unidentified impurity in the drug supply since reports of leukoencephalopathy have also occurred with intravenous heroin, inhaled oxycodone, and crack cocaine [72, 73].

Others drugs abused via inhalation that induce leukoencephalopathy include aromatic hydrocarbons. Toluene leukoencephalopathy is a well-characterized demyelinating disorder that spares the axons and afflicts central nervous system, producing neurobehavioral deficits. White matter abnormalities on MRI correspond with clinical severity $[74,75]$. Paradichlorobenzene is a very rare cause of leukoencephalopathy. Hallucinogens and amphetamines have been implicated as drugs of abuse associated with leukoencephalopathy. Although psilocybin has been implicated in posterior encephalopathy with cortical blindness and subacute multifocal cerebral demyelination after ingestion of "magic mushrooms," the association remains questionable, as with all drugs of abuse, because of the possibility of simultaneous exposure to other toxins [76]. Although 3,4methylenedioxymethamphetamine has been associated with iatrogenic injury to the central white matter through overly rapid correction of associated hyponatremia, it has also been associated with neuropsychiatric sequelae. Ongoing research suggests associated primary white matter pathology [77, 78].

Environmental toxins, especially in occupational settings, have produced leukoencephalopathy. After exposure to trimethyl tin from cleaning a tin tank, a 43-year-old man developed acute toxic leukoencephalopathy with dizziness, disorientation, visual hallucination, and agitation. MR images later revealed extensive abnormal signal intensities in white mater [79]. Long-term carbon disulfide exposure may induce encephalopathy, parkinsonism, pyramidal signs, cerebellar ataxia, cognitive impairments, and axonal polyneuropathy with diffuse hyperintense lesions in subcortical white matter, basal ganglia, and brain stem on MRI $[80,81]$. Carbon monoxide (CO) poisoning may precipitate neurologic sequelae with bilateral basal ganglion lesions and subcortical and periventricular white matter demyelination on MRI. White matter changes may not necessarily correlate with carboxyhemoglobin concentrations or neurologic sequelae $[82,83]$. Nonetheless, leukoencephalopathy is often difficult to attribute solely to $\mathrm{CO}$ poisoning when there is concomitant hypoxia.

What Diagnostic Strategy Should Be Pursued in a Suspected Toxin-Induced Leukoencephalopathy?

Diagnosis of a toxin-induced leukoencephalopathy relies heavily upon a history of exposure. Considering the rarity of toxin-induced leukoencephalopathy, organic, metabolic, infectious, genetic, demyelinating, structural, traumatic, or vascular etiologies should be excluded before pursuing more esoteric etiologies. Occupation, recreational activities, medications (prescribed, over the counter, homeopathic, and herbal), and abused/misused xenobiotics should be investigated. The onset and progression should be characterized and presence or absence of coasting noted. A detailed physical exam should characterize the attributes of disease. Particular cranial nerve, gait, reflex, sensory, or motor abnormalities may be typical or distinctive (e.g. facial nerve deficits in ethylene glycol or diethylene glycol exposure). Concomitant disease to other organ systems may also aid the diagnosis, such as renal tubular acidosis with toluene. The anatomic location(s) of central white matter disease and/or sparing may be consistent with a characteristic pattern, such as the predominant posterior lobe pathology in cases of chemotherapy-induced RPLS. When initial imaging is inconclusive for white matter disease, repeat imaging should be considered, as some toxins may have delayed or evolving manifestations. When applicable, concentrations of toxin in biological samples should be obtained to confirm exposure. When concentrations are unavailable or not well correlated with toxicity, the diagnosis may be primarily clinical. Toxin-specific antidotes, if available, should be implemented when indicated, such as chelation therapy for arsenic. In general, removal from the exposure and supportive care are the mainstays of treatment in toxin-induced leukoencephalopathies.

\section{Case Continuation}

Inability to discern an etiology and progressive clinical decline prompted toxicological considerations. The patient's history of pica was further explored. The family revealed he would ingest paradichlorobenzene (PDCB)containing mothballs and inhale mothball vapors. The patient would frequently "smoke" them by heating them with a flame to enhance vapor formation. This practice had been observed for at least 4 months prior to hospitalization. 


\section{What Is PDCB?}

Paradichlorobenzene (1,4-dichlorobenzene) is a chlorinated aromatic hydrocarbon, $\mathrm{C}_{6} \mathrm{H}_{4} \mathrm{Cl}_{2}$ (Fig. 2). It has been employed as a fumigant, insect repellant, and as an air, urinal, and latrine deodorizer in the form of compressed blocks or balls. PDCB may also be an intermediate in chemical synthesis of certain pesticides, dyes, and resins. At room temperature, it is in white crystalline form. Highly volatile with a strong distinctive odor, PDCB is a ubiquitous environmental air contaminant, commonly resulting in lowlevel human exposure.

PDCB is well absorbed via oral, inhaled, and subcutaneous routes. Inhaled PDCB rapidly distributes in human tissues, accumulates in adipose tissue, and is primarily renally eliminated (5-16\% eliminated $9-11 \mathrm{~h}$ after exposure) $[84,85]$. Cytochrome P450 CYP2E1 (along with CYP1A1 and CYP1A2) convert PDCB to its primary hepatic metabolite, 2,5-dichlorphenol (DCP) [86, 87]. Similarly, in other mammals, almost all PDCB is renally eliminated following biotransformation as free DCP or DCP sulfate or glucuronide conjugates [88]. Minor urinary metabolites include 2,5-dichlorohydroxyquinone, 2-( $N$-acyl-cysteine$S$-yl)-1,4-dichlorobenzene, and 2-( $N$-acyl-cysteine- $S$-yl)2,3-dihydro-3-hydroxy-1,3-hydroxy-1,4-dichlorobenzene $[40,89]$. Good correlation exists between PDCB in blood and DCP in urine at low, nonoccupational exposure [90], and urinary DCP is a suitable index for monitoring lowlevel exposure of PDCB in the general population [91].

\section{What Toxicity Is Reported from PDCB Exposure in Animal} Research?

The International Agency for Research on Cancer has reasonably anticipated PDCB to be a carcinogen (class 2B) [92]. Species-specific biotransformation of PDCB and production of reactive metabolites yield varied hepatotoxic and nephrotoxic profiles. Hepatocarcinogenicity is observed in mice likely due to increased microsomal production of reactive metabolites. In the rat, PDCB interferes with apoptosis to increase cell proliferation and liver weight, although it does not induce hepatocarcinogenesis [86, 93]. Both mice and rats are prone to nephrotoxicity from PDCB exposure. Mice do not develop true renal carcinogenicity in either sex while rats do so exclusively in males $[94,95]$. It has been suggested that renal toxicity in rats secondary to PDCB exposure may be an alpha- $2 \mu$-globulin-mediated

Fig. 2 Chemical structure of paradichlorobenzene

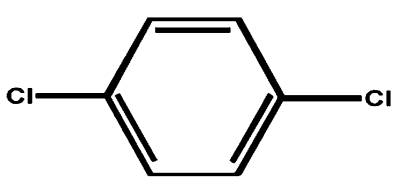

nephropathy [96, 97]. Similar renal pathology has been described in rabbits and guinea pigs [98, 99].

What Human Toxicity Is Reported from PDCB Exposure?

Although a potential for adverse health effects exists, significant clinical toxicity has not been reported from ambient exposure. Industrial workplace exposure may produce skin and mucous membrane toxicity manifesting as dermatitis, eye and nose irritation, and/or respiratory complaints [99, 100]. Long-term exposure risks are unclear. Although overshadowed by hepatic and renal toxicity, animal studies have demonstrated hematological toxicity. Anemias were evident in early reports of PDCB toxicity in humans $[95,98]$. A 3-year-old boy ingested PDCB demothing crystals and a 21-year-old postpartum female ingested PDCB toilet-freshener blocks [101, 102]. In both cases, there was complete recovery with removal from PDCB exposure. Another case described aplastic anemia in a 68-year-old woman who was exposed via inhalation to both naphthaleneand PDCB-containing products [103]. Diagnosis was made primarily by history; the 3-year-old had trace amounts of urinary 2,5-dichloroquinol [101]. Similar reports of anemia have been described with inhalational exposure in the midtwentieth century literature [104-106].

Other toxicities reported in the mid-twentieth century include sporadic hepatic, renal, and pulmonary pathology. PDCB was thought to be the cause of pulmonary granulomatosis in a 53-year-old woman who habitually scattered PDCB crystals on household furniture and carpeting and had unexplained persistent productive cough and dyspnea. Crystals were found within giant cells on her lung biopsy [107]. Four cases of acute cryptogenic fulminant hepatic failure were associated with chronic PDCB exposure [108]. Additionally, a 31-year-old woman who had worked for 2 years selling mothballs and other products containing PDCB developed hepatitis, subsequent portal hypertension, and esophageal varices [109]. Another report described a 69-year-old man with an anaphylactoid reaction, purpura, and subsequent glomerulonephritis after sitting in a chair that had been treated with PDCB flakes [110]. Although PDCB exposure was associated with these outcomes, it remains uncertain if it was the causative agent.

Neurotoxicity from chronic PDCB exposure is rare. The lipophilic properties of PDCB produce demyelination, resulting in leukoencephalopathy. The precise mechanism is unknown. Data on PDCB-induced neurotoxicity in humans are based upon nine published case reports dating back to 1961, totaling ten patients (Table 3) [111-119]. Neurotoxicity occurred after intentional misuse via inhalation and/or ingestion of PDCB-containing products. Only two cases of neurotoxicity quantitatively confirmed exposure $[112,114]$. Three others reported qualitative discovery 


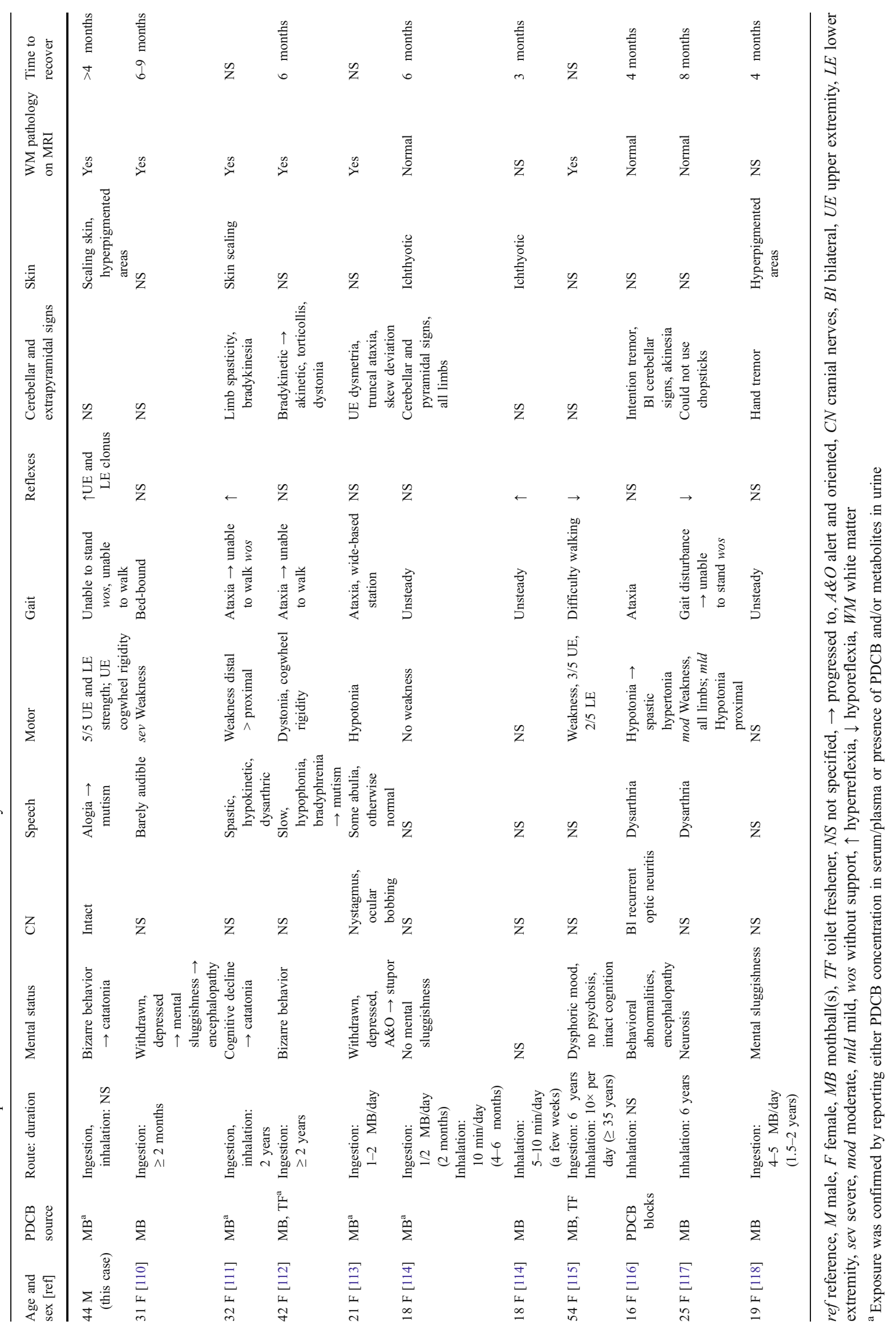


of urinary metabolites; two cases of neurotoxicity and one case of hemolytic anemia [101, 113, 115]. While isolated peripheral neurotoxicity may occur, central neurotoxicity with alteration in mental status is more common $[115,116]$. Cognitive, associated with bizarre behavior may be misinterpreted as psychiatric illness [111]. Mental status may deteriorate to catatonia, and ultimately invasive interventions to sustain nutrition may be required [112-114].

PDCB-induced neurotoxicity varies. Variable nystagmus, vision loss, and optic neuritis have occurred [114, 117]. Sensory deficits have not been described. Weakness and hypotonia without predilection for specific muscle groups are observed [111-114, 116, 118]. Symptoms may evolve and include spasticity and cogwheel-like rigidity $[113,117]$. Both hyporeflexia and hyperreflexia have been reported [112, 115, 116, 118].

Cerebellar and extrapyramidal signs and symptoms were reported in the majority of cases with limb spasticity, bradykinesia, dysmetria, ataxia, and tremor. Speech is often affected; deficits range from slow, spastic, hypophonic, dysarthric, bradyphrenic, abulic, or hypokinetic speech to complete mutism [111-114, 118]. Gait disturbance is a predominant feature reported in all cases of neurotoxicity from PDCB. The patient may deteriorate to the point of being unable to walk or even stand without support [111-119].

Skin findings are a distinctive feature, which when paired with neurotoxicity should raise suspicion for PDCB as the underlying etiology in an obscure leukoencephalopathy. Scaling, ichthyotic lesions, and/or hyperpigmentated areas are reported $[112,115,119]$. One case reported body odor of mothballs 1 month after hospitalization [114]. Microcytic anemia may be found in cases of PDCB neurotoxicity [111116, 118]. Ancillary testing is often normal and fails to determine an alternative etiology.

Neuroimaging, specifically MRI, can be especially helpful in supporting the diagnosis. Hyperintense signal in cerebral white matter is typically seen $[111-114,116]$. Specific anatomic locations include periventricular white matter, corpus callosum, deep cerebellar nuclei, parieto-occipital region, and internal capsule [113, 114]. There have been reports of PDCB neurotoxicity lacking such abnormalities on MRI; however, development of these findings may be delayed and may become more evident on subsequent imaging [113, $115,117,118]$. Computerized tomography is usually reported to be normal [111, 113, 114, 116-118]. Electroencephalogram results vary-normal studies, electrographic status epilepticus, activity slowing, diffuse disorganization, and rapid bursts are all described [111, 113-115, 117, 118].

Clinical toxicity is prolonged and patients may demonstrate coasting, remaining ill or further deteriorating before improving despite hospitalization, supportive care, and discontinuing exposure to PDCB [111, 113, 114, 119]. Onset of improvement has been reported to take up to 6 months [118]. Four case reports note as long as 6 to 9 months for complete recovery $[111,113,115,118]$. Complete resolution is possible if exposure ceases [115, 117-119].

\section{Case Continuation}

Approximately 1 month into hospitalization, a serum PDCB concentration was obtained. The result $(1.2 \mu \mathrm{g} / \mathrm{ml})$ prompted consultation with a medical toxicologist for assistance in management.

How Are Biological Markers of PDCB Exposure Interpreted?

Urinary DCP is a suitable index for monitoring PDCB exposure [91]. As a result of ambient exposure, DCP is almost universally present in urine without clinical toxicity, occupational exposure, or abuse. In 1,000 US adults adequately sampled from urban and rural residence, races, ethnicities, regions of the country, genders, and ages, $98 \%$ had detectable DCP in their urine and $96 \%$ had detectable PDCB in their blood without apparent clinical toxicity. Urinary DCP concentrations were $30 \mu \mathrm{g} / \mathrm{l}$ (median), $200 \mu \mathrm{g} / \mathrm{l}$ (mean), $460 \mu \mathrm{g} / \mathrm{l}$ (90th percentile), and $790 \mu \mathrm{g} / 1$ (95th percentile). The median, mean, 90th percentile, and 95th percentile concentrations of PDCB in blood were $0.33,2.1,4.8$, and $11 \mu \mathrm{g} / 1$, respectively. The concentrations of PDCB in blood ranged as high as $49 \mu \mathrm{g} / 1$ [90]. In a previous study of 197 otherwise healthy Arkansas children, 96\% had detectable urine DCP [120]. Similar environmental exposure has been demonstrated in Germany and Japan [121, 122].

Only two published case reports of neurotoxicity quantitatively confirmed exposure. A serum PDCB concentration of $34 \mu \mathrm{g} / \mathrm{ml}$ was present in a case of leukoencephalopathy following acute-on-chronic exposure [112]. In a second case, following exposure cessation, PDCB plasma concentrations 2 weeks and 1 month later were 0.50 and $0.39 \mu \mathrm{g} / \mathrm{ml}$ [114]. Two other cases of neurotoxicity and one case of hemolytic anemia detected PDCB or its metabolites without quantification [101, 113, 115]. Elimination may be slow following chronic administration due to significant adipose tissue deposition [85, 91]. Coasting is typical, and serum concentrations may be low despite clinical toxicity. Until further data are available, PDCB leukoencephalopathy remains a diagnosis of exclusion, relying on history, clinical signs of neurotoxicity, and MRI findings.

What Treatment Options Are Available for Patients with PDCB-Induced Leukoencephalopathy?

No specific antidote for PDCB-induced leukoencephalopathy exists. Treatment emphasizes removal from exposure 
and supportive care. Patients may require invasive procedures to sustain life and provide adequate nutrition such as nasogastric or percutaneous enterogastric feeding tubes during the prolonged elimination period. Efforts focus upon preventing infection and other complications of prolonged hospitalization. Physical therapy may ameliorate muscle wasting, as lack of mobility is prominent feature in cases of PDCB-induced leukoencephalopathy. Patients may require transfer to a rehabilitation facility before fully recovering. Finally, psychiatric consultation may be warranted as the toxicity often originates from abuse of PDCB.

\section{Case Conclusion}

Three months after hospitalization, the patient began to develop slight improvement described as increased responsiveness. A noncontrast $\mathrm{CT}$ of the brain performed days prior to transfer demonstrated subtle low attenuation in the periventricular white matter. The patient was transferred to a skilled nursing facility for continued care.

Acknowledgements This case was presented at the ACMT Medical Toxicology 11th Annual CPC Competition at the 2009 North American Congress of Clinical Toxicology Annual Meeting, San Antonio, TX, USA, September 22, 2009.

\section{References}

1. Hinchey J, Chaves C, Appignani B, Breen J, Pao L, Wang A, Pessin MS, Lamy C, Mas JL, Caplan LR (1996) A reversible posterior leukoencephalopathy syndrome. N Engl J Med 334:494-500

2. Sharshar T, Gray F, Poron F, Raphael JC, Gajdos P, Annane D (2002) Multifocal necrotizing leukoencephalopathy in septic shock. Crit Care Med 30:2371-2375

3. van der Knaap MS, Breiter SN, Naidu S, Hart AA, Valk J (1999) Defining and categorizing leukoencephalopathies of unknown origin: MR imaging approach. Radiology 213:121-133

4. Hesselink JR (2006) Differential diagnostic approach to MR imaging of white matter diseases. Top Magn Reson Imaging 17:243-263

5. Costello DJ, Eichler AF, Eichler FS (2009) Leukodystrophies: classification, diagnosis, and treatment. Neurologist 15:319-328

6. Vanderver A (2005) Tools for diagnosis of leukodystrophies and other disorders presenting with white matter disease. Curr Neurol Neurosci Rep 5:110-118

7. Healton EB, Savage DG, Brust JC, Garrett TJ, Lindenbaum J (1991) Neurologic aspects of cobalamin deficiency. Medicine (Baltimore) 70:229-245

8. Chatterjee A, Yapundich R, Palmer CA, Marson DC, Mitchell GW (1996) Leukoencephalopathy associated with cobalamin deficiency. Neurology 46:832-834

9. Reynolds E (2006) Vitamin $B_{12}$, folic acid, and the nervous system. Lancet Neurol 5:949-960

10. Celik O, Hascalik S (2003) Reversible posterior leukoencephalopathy in eclampsia. Int J Gynaecol Obstet 82:67-69
11. Rosenberg GA (2009) Inflammation and white matter damage in vascular cognitive impairment. Stroke 40:S20-S23

12. Oh U, Gupta R, Krakauer JW, Khandji AG, Chin SS, Elkind MS (2004) Reversible leukoencephalopathy associated with cerebral amyloid angiopathy. Neurology 62:494-497

13. Cinque P, Koralnik IJ, Gerevini S, Miro JM, Price RW (2009) Progressive multifocal leukoencephalopathy in HIV-1 infection. Lancet Infect Dis 9:625-636

14. Gongvatana A, Schweinsburg BC, Taylor MJ, Theilmann RJ, Letendre SL, Alhassoon OM, Jacobus J, Woods SP, Jernigan TL, Ellis RJ, Frank LR, Grant I, Charter Group (2009) White matter tract injury and cognitive impairment in human immunodeficiency virus-infected individuals. J Neurovirology 15:187-195

15. Souraud JB, Faivre A, Waku-Kouomou D, Gaillard T, Aouad N, Meaudre E, Wild FT, Fouet B, Soulard R (2009) Adult fulminant subacute sclerosing panencephalitis: pathological and molecular studies - a case report. Clin Neuropathol 28:213-218

16. Hu W, Lucchinetti CF (2009) The pathological spectrum of CNS inflammatory demyelinating diseases. Semin Immunopathol 31:439-453

17. Canellas AR, Gols AR, Izquierdo JR, Subirana MT, Gairin XM (2007) Idiopathic inflammatory-demyelinating diseases of the central nervous system. Neuroradiology 49:393-409

18. Fleming FJ, Vytopil M, Chaitow J, Jones HR Jr, Darras BT, Ryan MM (2005) Thalidomide neuropathy in childhood. Neuromuscul Disord 15:172-176

19. Burns TM, Shneker BF, Juel VC (2001) Gasoline sniffing multifocal neuropathy. Pediatr Neurol 25:419-421

20. Smith AG, Albers JW (1997) $n$-Hexane neuropathy due to rubber cement sniffing. Muscle Nerve 20:1445-1450

21. Windebank AJ, Grisold W (2008) Chemotherapy-induced neuropathy. J Peripher Nerv Syst 13:27-46

22. Berger AR, Schaumburg HH, Schroeder C, Apfel S, Reynolds R (1992) Dose response, coasting, and differential fiber vulnerability in human toxic neuropathy: a prospective study of pyridoxine neurotoxicity. Neurology 42:1367-1370

23. Berger AR, Arezzo JC, Schaumburg HH, Skowron G, Merigan T, Bozzette S, Richman D, Soo W (1993) 2',3'-dideoxycytidine (ddC) toxic neuropathy: a study of 52 patients. Neurology 43:358-362

24. Dietrich J, Han R, Yang Y, Mayer-Proschel M, Noble M (2006) CNS progenitor cells and oligodendrocytes are targets of chemotherapeutic agents in vitro and in vivo. J Biol 5:22

25. Crossen JR, Garwood D, Glatstein E, Neuwelt EA (1994) Neurobehavioral sequelae of cranial irradiation in adults: a review of radiation-induced encephalopathy. J Clin Oncol 12:627-642

26. Giglio P, Gilbert MR (2003) Cerebral radiation necrosis. Neurologist 9:180-188

27. Blaes AH, Santa-Cruz KS, Lee CK, Hui SK, Peterson BA (2008) Necrotizing leukoencephalopathy following CHOP chemotherapy. Leuk Res 32:1611-1614

28. Hook CC, Kimmel DW, Kvols LK, Scheithauer BW, Forsyth PA, Rubin J, Moertel CG, Rodriguez M (1992) Multifocal inflammatory leukoencephalopathy with 5-fluorouracil and levamisole. Ann Neurol 31:262-267

29. Oka M, Terae S, Kobayashi R, Sawamura Y, Kudoh K, Tha KK, Yoshida M, Kaneda M, Suzuki Y, Miyasaka K (2003) MRI in methotrexate-related leukoencephalopathy: disseminated necrotising leukoencephalopathy in comparison with mild leukoencephalopathy. Neuroradiology 45:493-497

30. Garg RK (2003) Postpartum posterior leukoencephalopathy syndrome. J Assoc Phys India 51:211-213

31. Ricard D, Taillia H, Renard JL (2009) Brain damage from anticancer treatments in adults. Curr Opin Oncol 21:559-565

32. Pavlakis SG, Frank Y, Chusid R (1999) Hypertensive encephalopathy, reversible occipitoparietal encephalopathy, or reversible 
posterior leukoencephalopathy: three names for an old syndrome. J Child Neurol 14:277-281

33. Ito $Y$, Arahata $Y$, Goto $Y$, Hirayama M, Nagamutsu M, Yasuda T, Yanagi T, Sobue G (1998) Cisplatin neurotoxicity presenting as reversible posterior leukoencephalopathy syndrome. AJNR Am J Neuroradiol 19:415-417

34. Kwon EJ, Kim SW, Kim KK, Seo HS, Kim do Y (2009) A case of gemcitabine and cisplatin associated posterior reversible encephalopathy syndrome. Cancer Res Treat 41:53-55

35. Rajasekhar A, George TJ Jr (2007) Gemcitabine-induced reversible posterior leukoencephalopathy syndrome: a case report and review of the literature. Oncologist 12:1332-1335

36. Edwards MJ, Walker R, Vinnicombe S, Barlow C, MacCallum P, Foran JM (2001) Reversible posterior leukoencephalopathy syndrome following CHOP chemotherapy for diffuse large Bcell lymphoma. Ann Oncol 12:1327-1329

37. Ziereisen F, Dan B, Azzi N, Ferster A, Damry N, Christophe C (2006) Reversible acute methotrexate leukoencephalopathy: atypical brain MR imaging features. Pediatr Radiol 36:205-212

38. Kelly K, Kalachand R, Murphy P (2008) Bortezomib-induced reversible posterior leucoencephalopathy syndrome. Br J Haematol 141:566

39. Martin G, Bellido L, Cruz JJ (2007) Reversible posterior leukoencephalopathy syndrome induced by sunitinib. J Clin Oncol 25:3559

40. Hissink AM, Dunnewijk R, van Ommen B, van Bladeren PJ (1997) Kinetics and metabolism of 1,4-dichlorobenzene in male Wistar rats: no evidence for quinone metabolites. Chem Biol Interact 103:17-33

41. Rathi B, Azad RK, Vasudha N, Hissaria P, Sawlani V, Gupta RK (2002) L-Asparaginase-induced reversible posterior leukoencephalopathy syndrome in a child with acute lymphoblastic leukemia. Pediatr Neurosurg 37:203-205

42. Tsagalou EP, Anastasiou-Nana MI, Margari ZJ, Vassilopoulos D (2007) Possible everolimus-induced, severe, reversible encephalopathy after cardiac transplantation. J Heart Lung Transplant 26:661664

43. Levy CF, Oo KZ, Fireman F, Pierre L, Bania MA, Sadanandan S, Yamashiro DJ, Bender JL (2009) Reversible posterior leukoencephalopathy syndrome in a child treated with bevacizumab. Pediatr Blood Cancer 52:669-671

44. Irvin W, MacDonald G, Smith JK, Kim WY (2007) Dexamethasoneinduced posterior reversible encephalopathy syndrome. J Clin Oncol 25:2484-2486

45. Yoshimoto T, Yagi K, Inoue M, Okamura T, Yasui M, Cyayama K, Nakano T, Tsuchiya H, Kawa K (1997) Leukoencephalopathy probably caused by tacrolimus hydrate after stem cell transplantation in a girl with MDS 7 monosomy. Rinsho Ketsueki 38:616-621

46. Kastrup O, Diener HC (2008) TNF-antagonist etanercept induced reversible posterior leukoencephalopathy syndrome. J Neurol 255:452-453

47. Kamar N, Kany M, Bories P, Ribes D, Izopet J, Durand D, Rostaing L (2001) Reversible posterior leukoencephalopathy syndrome in hepatitis $\mathrm{C}$ virus-positive long-term hemodialysis patients. Am J Kidney Dis 37(E29):1-6

48. Re D, Bamborschke S, Feiden W, Schroder R, Lehrke R, Diehl V, Tesch H (1999) Progressive multifocal leukoencephalopathy after autologous bone marrow transplantation and alphainterferon immunotherapy. Bone Marrow Transplant 23:295-298

49. de Oliveira RA, Fechine LM, Neto FC, Nicodemus JM, Silva GB Jr, Silva LS (2008) Posterior reversible encephalopathy syndrome (PRES) induced by cyclosporine use in a patient with collapsing focal glomeruloesclerosis. Int Urol Nephrol 40:1095-1098

50. Delanty N, Vaughan C, Frucht S, Stubgen P (1997) Erythropoietinassociated hypertensive posterior leukoencephalopathy. Neurology 49:686-689
51. Kunschner L, Scott TF (2005) Sustained recovery of progressive multifocal leukoencephalopathy after treatment with IL-2. Neurology 65:1510

52. Przepiorka D, Jaeckle KA, Birdwell RR, Fuller GN, Kumar AJ, Huh YO, McCutcheon I (1997) Successful treatment of progressive multifocal leukoencephalopathy with low-dose interleukin-2. Bone Marrow Transplant 20:983-987

53. Xu N, Zhou W, Li S, Zhou G, Zhang N, Liang J (2009) Clinical and MRI characteristics of levamisole-induced leukoencephalopathy in 16 patients. J Neuroimaging 19:326-331

54. Wu VC, Huang JW, Lien HC, Hsieh ST, Liu HM, Yang CC, Lin YH, Hwang JJ, Wu KD (2006) Levamisole-induced multifocal inflammatory leukoencephalopathy: clinical characteristics, outcome, and impact of treatment in 31 patients. Medicine (Baltimore) 85:203-213

55. Liu JS, Chang YY, Chen WH, Chen SS (1995) Amphotericin Binduced leukoencephalopathy in a patient with cryptococcal meningitis. J Formos Med Assoc 94:432-434

56. Walker RW, Rosenblum MK (1992) Amphotericin B-associated leukoencephalopathy. Neurology 42:2005-2010

57. Ferry T, Ponceau B, Simon M, Issartel B, Petiot P, Boibieux A, Biron F, Chidiac C, Peyramond D (2005) Possibly linezolidinduced peripheral and central neurotoxicity: report of four cases. Infection 33:151-154

58. Mahad DJ, Hellden A, Jarvis J, Mitra D, Gholkar A, Chinnery PF (2005) Aciclovir induced posterior leucoencephalopathy. J Neurol Neurosurg Psychiatry 76:1308-1309

59. Shuman RM, Leech RW, Alvord ECJ (1975) Neurotoxicity of hexachlorophene in humans. II. A clinicopathological study of 46 premature infants. Arch Neurol 32:320-325

60. Nishimune T, Watanabe Y, Okazaki H, Akai H (2000) Thiamin is decomposed due to Anaphe spp. entomophagy in seasonal ataxia patients in Nigeria. J Nutr 130:1625-1628

61. Kumar N (2010) Neurologic presentations of nutritional deficiencies. Neurol Clin 28:107-170

62. Spampinato MV, Castillo M, Rojas R, Palacios E, Frascheri L, Descartes F (2005) Magnetic resonance imaging findings in substance abuse: alcohol and alcoholism and syndromes associated with alcohol abuse. Top Magn Reson Imaging 16:223-230

63. Rubinstein D, Escott E, Kelly JP (1995) Methanol intoxication with putaminal and white matter necrosis: MR and CT findings. AJNR Am J Neuroradiol 16:1492-1494

64. Freilich BM, Altun Z, Ramesar C, Medalia A (2007) Neuropsychological sequelae of ethylene glycol intoxication: a case study. Appl Neuropsychol 14:56-61

65. Hantson P, Duprez T (2006) The value of morphological neuroimaging after acute exposure to toxic substances. Toxicol Rev 25:87-98

66. Salgado RA, Jorens PG, Baar I, Cras P, Hans G, Parizel PM (2009) Methadone-induced toxic leukoencephalopathy: MR imaging and MR proton spectroscopy findings. AJNR Am J Neuroradiol 31:565-566

67. Anselmo M, Campos Rainho A, do Carmo Vale M, Estrada J, Valente R, Correia M, Vieira JP, Barata D (2006) Methadone intoxication in a child: toxic encephalopathy? J Child Neurol 21:618-620

68. Wolters EC, van Wijngaarden GK, Stam FC (1982) Leukoencephalopathy after inhaling "heroin" pyrosylate. Lancet 2:1233-1237

69. Kriegstein AR, Shungu DC, Millar WS, Armitage BA, Brust JC, Chillrud S, Goldman J, Lynch T (1999) Leukoencephalopathy and raised brain lactate from heroin vapor inhalation ("chasing the dragon"). Neurology 53:1765-1773

70. Offiah C, Hall E (2008) Heroin-induced leukoencephalopathy: characterization using MRI, diffusion-weighted imaging, and MR spectroscopy. Clin Radiol 63:146-152 
71. Hagel J, Andrews G, Vertinsky T, Heran MK, Keogh C (2005) "Chasing the dragon"-imaging of heroin inhalation leukoencephalopathy. Can Assoc Radiol J 56:199-203

72. McKinney AM, Kieffer SA, Paylor RT, SantaCruz KS, Kendi A, Lucato L (2009) Acute toxic leukoencephalopathy: potential for reversibility clinically and on MRI with diffusion-weighted and FLAIR imaging. AJR Am J Roentgenol 193:192-206

73. Ryan A, Molloy FM, Farrell MA, Hutchinson M (2005) Fatal toxic leukoencephalopathy: clinical, radiological, and necropsy findings in two patients. J Neurol Neurosurg Psychiatry 76:1014-1016

74. Rosenberg NL, Kleinschmidt-DeMasters BK, Davis KA, Dreisbach JN, Hormes JT, Filley CM (1988) Toluene abuse causes diffuse central nervous system white matter changes. Ann Neurol 23:611-614

75. Filley CM, Halliday W, Kleinschmidt-DeMasters BK (2004) The effects of toluene on the central nervous system. J Neuropathol Exp Neurol 63:1-12

76. Bickel M, Ditting T, Watz H, Roesler A, Weidauer S, Jacobi V, Gueller S, Betz C, Fichtlscherer S, Stein J (2005) Severe rhabdomyolysis, acute renal failure and posterior encephalopathy after "magic mushroom" abuse. Eur J Emerg Med 12:306-308

77. Campbell GA, Rosner MH (2008) The agony of ecstasy: MDMA (3,4-methylenedioxymethamphetamine) and the kidney. Clin J Am Soc Nephrol 3:1852-1860

78. Cowan RL, Roberts DM, Joers JM (2008) Neuroimaging in human MDMA (ecstasy) users. Ann N Y Acad Sci 1139:291298

79. Hwang CH (2009) The sequential magnetic resonance images of tri-methyl tin leukoencephalopathy. Neurol Sci 30:153-158

80. Huang CC (2004) Carbon disulfide neurotoxicity: Taiwan experience. Acta Neurol Taiwan 13:3-9

81. Ku MC, Huang CC, Kuo HC, Yen TC, Chen CJ, Shih TS, Chang HY (2003) Diffuse white matter lesions in carbon disulfide intoxication: microangiopathy or demyelination. Eur Neurol 50:220-224

82. Parkinson RB, Hopkins RO, Cleavinger HB, Weaver LK, Victoroff J, Foley JF, Bigler ED (2002) White matter hyperintensities and neuropsychological outcome following carbon monoxide poisoning. Neurology 58:1525-1532

83. Miura T, Mitomo M, Kawai R, Harada K (1985) CT of the brain in acute carbon monoxide intoxication: characteristic features and prognosis. AJNR Am J Neuroradiol 6:739-742

84. Yoshida T, Andoh K, Fukuhara M (2002) Urinary 2,5dichlorophenol as biological index for p-dichlorobenzene exposure in the general population. Arch Environ Contam Toxicol 43:481-485

85. Morita M, Ohi G (1975) Para-dichlorobenzene in human tissue and atmosphere in Tokyo metropolitan area. Environ Pollut 8:269

86. Hissink AM, Oudshoorn MJ, Van Ommen B, Van Bladeren PJ (1997) Species and strain differences in the hepatic cytochrome P450-mediated biotransformation of 1,4-dichlorobenzene. Toxicol Appl Pharmacol 145:1-9

87. Bogaards JJ, van Ommen B, Wolf CR, van Bladeren PJ (1995) Human cytochrome P450 enzyme selectivities in the oxidation of chlorinated benzenes. Toxicol Appl Pharmacol 132:44-52

88. Hawkins DR, Chasseaud LF, Woodhouse RN, Cresswell DG (1980) The distribution excretion and biotransformation of $p$ dichloro $\left[{ }^{14} \mathrm{C}\right]$ benzene in rats after repeated inhalation, oral and subcutaneous doses. Xenobiotica 10:81-95

89. Klos C, Dekant W (1994) Comparative metabolism of the renal carcinogen 1,4-dichlorobenzene in rat: identification and quantitation of novel metabolites. Xenobiotica 24:965-976

90. Hill RH Jr, Ashley DL, Head SL, Needham LL, Pirkle JL (1995) $p$-Dichlorobenzene exposure among 1,000 adults in the United States. Arch Environ Health 50:277-280
91. Yoshida T, Andoh K, Kosaka H, Kumagai S, Matsunaga I, Akasaka S, Nakamura S, Oda H, Fukuhara M (2002) Inhalation toxicokinetics of $p$-dichlorobenzene and daily absorption and internal accumulation in chronic low-level exposure to humans. Arch Toxicol 76:306-315

92. IARC Working Group on the Evaluation of Carcinogenic Risks to Humans (1999) Dichlorobenzenes. In: IARC monographs on the evaluation of carcinogenic risks to humans. Some chemicals that cause tumours of the kidney or urinary bladder in rodents and some other substances, vol. 73. IARC Press, Lyons, pp 223-276

93. Eldridge SR, Goldsworthy TL, Popp JA, Butterworth BE (1992) Mitogenic stimulation of hepatocellular proliferation in rodents following 1,4-dichlorobenzene administration. Carcinogenesis 13:409-415

94. Lake BG, Cunninghame ME, Price RJ (1997) Comparison of the hepatic and renal effects of 1,4-dichlorobenzene in the rat and mouse. Fundam Appl Toxicol 39:67-75

95. Aiso $\mathrm{S}$, Arito $\mathrm{H}$, Nishizawa $\mathrm{T}$, Nagano $\mathrm{K}$, Yamamoto $\mathrm{S}$, Matsushima T (2005) Thirteen-week inhalation toxicity of $p$ dichlorobenzene in mice and rats. J Occup Health 47:249-260

96. Umemura T, Kodama Y, Kurokawa Y, Williams GM (2000) Lack of oxidative DNA damage or initiation of carcinogenesis in the kidneys of male F344 rats given subchronic exposure to $p$ dichlorobenzene $(\mathrm{pDCB})$ at a carcinogenic dose. Arch Toxicol 74:54-59

97. Charbonneau M, Strasser J Jr, Lock EA, Turner MJ Jr, Swenberg JA (1989) Involvement of reversible binding to alpha $2 \mathrm{u}-$ globulin in 1,4-dichlorobenzene-induced nephrotoxicity. Toxicol Appl Pharmacol 99:122-132

98. Zupko AG, Edwards LD (1949) A toxicological study of $p$ dichlorobenzene. J Am Pharm Assoc 38:124-131

99. Hollingsworth RL, Hoyle HR, Oyen F, Rowe VK, Spencer HC (1956) Toxicity of paradichlorobenzene; determinations on experimental animals and human subjects. AMA Arch Ind Health 14:138-147

100. EPA US (2003) Toxicological review and summary documents for dichlorobenzenes (external review draft). EPA/635/R-03/015. US Environmental Protection Agency, Cincinnati

101. Hallowell M (1959) Acute haemolytic anaemia following the ingestion of paradichlorobenzene. Arch Dis Child 34:74-77

102. Campbell DM, Davidson RJ (1970) Toxic haemolytic anaemia in pregnancy due to a pica for paradichlorobenzene. J Obstet Gynaecol Br Commonw 77:657-659

103. Harden RA, Baetjer AM (1978) Aplastic anemia following exposure to paradichlorobenzene and naphthalene. J Occup Med 20:820-822

104. Wallgren K (1953) Chronische Vergiftungen bel der Herstellung von Mottenmitteln, die grosstenteils aus paradichlorobenzol bestehen. Zentralbl Arbeitsmed Arbeitsschutz 3:14-15

105. Petit G, Champeix J (1948) Existe-t-il une intoxication par le paradichlorobenzene? Arch Mal Prof 9:311-313

106. Girard R, Toldt F, Martin P, Bourret J (1969) Hemopathies graves et exposition a des derives chlores du benzene (a propas de 7 cas). J Med (Lyon) 50:771-773

107. Weller RW, Crellin AJ (1953) Pulmonary granulomatosis following extensive use of paradichlorobenzene. AMA Arch Intern Med 91:408-413

108. Cotter LH (1953) Paradichlorobenzene poisoning from insecticides. N Y State J Med 53:1690-1692

109. Sumers J, Fuhrman M, Kelman A (1952) Hepatitis with concomitant esophageal varices following exposure to moth ball vapors. N Y State J Med 52:1048-1049

110. Nalbandian RM, Pearce JF (1965) Allergic purpura induced by exposure to $p$-dichlorobenzene. Confirmation by indirect basophil degranulation test. JAMA 194:828-829 
111. Murray SB, Dwight-Johnson M, Levy MR (2009) Mothball induced encephalopathy presenting as depression: it's all in the history. Gen Hosp Psychiatry. doi:10.1016/j.genhosppsych.2009.04.008

112. Kumar N, Dale LC, Wijdicks EF (2009) Mothball mayhem: relapsing toxic leukoencephalopathy due to p-dichlorobenzene neurotoxicity. Ann Intern Med 150:362-363

113. Cheong R, Wilson RK, Cortese IC, Newman-Toker DE (2006) Mothball withdrawal encephalopathy: case report and review of paradichlorobenzene neurotoxicity. Subst Abus 27:63-67

114. Avila E, Schraeder P, Belliappa A, Faro S (2006) Pica with paradichlorobenzene mothball ingestion associated with toxic leukoencephalopathy. J Neuroimaging 16:78-81

115. Feuillet L, Mallet S, Spadari M (2006) Twin girls with neurocutaneous symptoms caused by mothball intoxication. N Engl J Med 355:423-424

116. Weintraub E, Gandhi D, Robinson C (2000) Medical complications due to mothball abuse. South Med J 93:427-429
117. Reygagne A, Garnier R, Chataigner D, Echenne B, Efthymiou ML (1992) Encephalopathy due to repeated voluntary inhalation of paradichlorobenzene. J Toxicol Clin Exp 12:247-250

118. Miyai I, Hirono N, Fujita M, Kameyama M (1988) Reversible ataxia following chronic exposure to paradichlorobenzene. J Neurol Neurosurg Psychiatry 51:453-454

119. Frank S, Cohen HJ (1961) Fixed drug eruption due to paradichlorobenzene. N Y State J Med 61:4079

120. Hill RH Jr, To T, Holler JS, Fast DM, Smith SJ, Needham LL, Binder S (1989) Residues of chlorinated phenols and phenoxy acid herbicides in the urine of Arkansas children. Arch Environ Contam Toxicol 18:469-474

121. Angerer J, Heinzow B, Schaller K, Weltle D (1992) Determination of environmental caused chlorophenol levels in urine of the general population. Fresenius' J Anal Chem 342:433-438

122. Morita S, Miwa H, Kihira T, Kondo T (2003) Cerebellar ataxia and leukoencephalopathy associated with cobalamin deficiency. J Neurol Sci 216:183-184 